\title{
Evaluación del ensilado de residuos de pescado y de cabeza de langostino fermentado con Lactobacillus fermentus aislado de cerdo
}

\author{
Evaluation of fish residues and shrimp head silages fermented with Lactobacillus \\ fermentus isolated from pig
}

\author{
Wendy Elizabeth Castillo García ${ }^{1}$, Héctor Alfredo Sánchez Suárez ${ }^{2,4}$, \\ Gloria María Ochoa Mogollón ${ }^{3}$
}

\section{Resumen}

\begin{abstract}
El objetivo del estudio fue determinar las características viables y nutricionales del ensilado de cabeza de langostino y de residuos de pescado destinado para la alimentación de cerdos. En el proceso de conservación se utilizó la melaza y el polvillo de arroz como sustrato y Lactobacullus fermentus, obtenido del tracto digestivo del lechón, como fermentador. Se tomaron registros de temperatura, $\mathrm{pH}$, porcentaje de acidez, así como características organolépticas y nutritivas en los primeros 30 días de conservación. Los tratamientos fueron $\mathrm{T} 1=$ Cabeza de langostino con melaza y yogurt; $\mathrm{T} 2=$ Cabeza de langostino con polvillo y yogurt; T3 = Residuo de pescado con melaza y yogurt; y T4 = Residuo de pescado con polvillo y yogurt. T1 y T3 presentaron acidez y pH bajo, así como temperatura baja en la primera semana, llegando a estabilizar el proceso el día 15. La fermentación de T2 y T4 fue inadecuada (no viable). Los microorganismos aerobios mesófilos, levaduras y hongos estuvieron dentro del límite aceptable para alimento balanceado y donde la bacteria patógena Salmonella sp estuvo ausente. El contenido de proteína cruda mejoró en $2.03 \%$ en T 1 y $2.32 \%$ en T3. Se concluye que los ensilados T1 y $\mathrm{T} 3$ son adecuados y se estabilizan a partir del día 15 , sin contener microorganismos patógenos y el contenido proteico se ajusta a las fuentes nutricionales de origen animal para la alimentación porcina.
\end{abstract}

Palabras clave: ensilado; bacterias ácido-lácticas; fermentación; residuos orgánicos

\footnotetext{
${ }^{1}$ Escuela de Agroindustria, Facultad de Ciencias Agrarias, Universidad Nacional de Tumbes, Perú

${ }^{2}$ Escuela de Medicina Veterinaria y Zootecnia, Facultad de Ciencias Agrarias, Universidad Nacional de Tumbes, Perú

${ }^{3}$ Laboratorio de Biología Molecular, Facultad de Salud, Universidad Nacional de Tumbes, Perú

${ }^{4}$ E-mail: hsanchezs@untumbes.edu.pe
}

Recibido: 28 de enero de 2019

Aceptado para publicación: 2 de octubre de 2019 
The aim of this study was to determine the viability and nutritional characteristics of shrimp head silage and fish waste destined for pig feeding. In the conservation process, molasses and rice powder were used as a substrate and Lactobacullus fermentus, obtained from the digestive tract of the piglet, as a fermenter. Temperature, $\mathrm{pH}$ and percentage of acidity data were recorded, as well as organoleptic and nutritional characteristics in the first 30 days of conservation. The treatments were $\mathrm{T} 1=$ Shrimp head with molasses and yogurt; T2 = Shrimp head with rice powder and yogurt; T3 = Fish residue with molasses and yogurt; and T4 $=$ Fish residue with rice powder and yogurt. T1 and T3 presented acidity and low $\mathrm{pH}$, as well as low temperature during the first week, stabilizing the process on day 15. The fermentation of T2 and T4 was inadequate (not feasible). Aerobic mesophilic microorganisms, yeasts and fungi were within the acceptable limit in balanced feeds and the pathogenic bacterium Salmonella sp was absent. Crude protein content improved by $2.03 \%$ in $\mathrm{T} 1$ and $2.32 \%$ in T3. It is concluded that the $\mathrm{T} 1$ and $\mathrm{T} 3$ silages are adequate and stabilize from day 15 , without containing pathogenic microorganisms and the protein content is according to the nutritional sources of animal origin for pig feeding.

Key words: silage; lactic acid bacteria; fermentation; organic waste

\section{INTRODUCCIÓN}

La generación de residuos en el procesamiento pesquero puede estimarse entre 55 a $60 \%$ de la materia prima que ingresa en las plantas pesqueras y de $30 \%$ en el procesamiento de langostino (Ponce y Gernat, 2002). El vertido de estos residuos en basurales a cielo abierto o secado como harina artesanal ocasiona la propagación de roedores, insectos y aves marinas en general (Sánchez y Ochoa, 2016). La descomposición producida por enzimas proteolíticas propias de los mismos residuos orgánicos y por microorganismos patógenos es una fuente de contaminación latente para los pobladores que viven en zonas aledañas. Además, uno de los principales compuestos producidos por la acción bacteriana en estos residuos son los óxidos de trimetilamina, que ocasionan el hedor característico del pescado descompuesto (Ambrosio, 2004).

La alimentación de los animales de granja representa entre el 60 y $80 \%$ de los costos totales de producción; donde la disponibilidad limitada de la proteína es motivo del alto costo de las dietas (Balfagón y Jiménez, 2014). El insumo de origen animal de mayor uso es la harina de pescado por su alto contenido proteico; sin embargo, su alto precio en el mercado demanda la búsqueda de fuentes alternas de proteínas (Castro y Martínez, 2015; Báñez et al., 2017). Un insumo alimenticio proteico para uso animal es aquel que contiene más del $20 \%$ de proteína en su composición nutricional (Wattiaux et al., 1998).

Una de las alternativas viables desde el punto de vista ambiental y económico la constituye el ensilado biológico, tecnología de fácil aplicación que aprovecha los residuos orgánicos para generar productos con valor económico y con cualidades nutritivas (Lezcano et al., 2015; Montaño et al., 2016). El ensilado biológico se define como un producto semilíquido o pastoso, que aprovecha los residuos de desechos de la industria pesquera no apto para consumo humano (González y Marin, 2005), logrando su estabililidad a partir del decimo día de incubación (Samuels et al., 1991). La producción de ácido se consigue mediante un 
proceso de fermentación controlada con bacterias ácido-lácticas (BAL) sobre carbohidratos, obteniéndose un producto estable, con buenas cualidades nutritivas y de protección contra bacterias patógenas y de putrefacción (Holguín et al., 2009; Hernández et al., 2015; Caicedo et al., 2018).

El objetivo de este trabajo fue producir ensilados biológicos a partir de cabeza de langostino y residuos de pescado como materia prima y con carbohidratos fermentadores alternativos (melaza y polvillo de arroz), y como microrganismo de fermentación a Lactobacullus fermentus, utilizando inóculos fermentadores obtenidos del estómago del cerdo, con el fin de determinar el momento óptimo de su viabilidad al evaluar las características fisicoquímicas y nutritivas para su posible empleo en la alimentación animal.

\section{Materiales y Métodos}

La investigación se realizó en las instalaciones del laboratorio de cárnicos de la Escuela de Agroindustrias de la Facultad de Ciencias Agrarias (FCA) y laboratorio de biología molecular de la Facultad de Ciencias de la Salud (FCS), ambos de la Universidad Nacional de Tumbes (UNT), Perú.

Las muestras de cabeza de langostino $(18 \mathrm{~kg})$ fueron recolectadas en una planta pesquera y los residuos de pescado $(10 \mathrm{~kg})$ resultantes del fileteado del pez espejo (Selene peruviana) en el área de venta de pescado en el mercado de Tumbes. Ambas muestras fueron recolectadas en estado fresco. Como tratamientos se consideraron los ensilados preparados con: $\mathrm{T} 1=$ Cabeza de langostino con melaza y yogurt; $\mathrm{T} 2=$ Cabeza de langostino con polvillo y yogurt; T3 = Residuo de pescado con melaza y yogurt; y $\mathrm{T} 4$ $=$ Residuo de pescado con polvillo y yogurt.

\section{Preparación del Ensilado Biológico}

El ensilado fue preparado siguiendo los protocolos establecidos (Martínez Prada, 2003; Sánchez y Ochoa, 2016; SánchezTrujillo et al., 2016) en tres etapas: preparacion del inóculo, prepracion del yogurt y preparación del ensilado biológico.

\section{Preparación del inóculo bacteriano}

Para preparar el inóculo bacteriano que se incorpora al ensilado como fermentador se utilizó leche fresca y bacterias ácidolácticas (BAL) nativas, aisladas e identificadas por su genoma del tracto digestivo del cerdo (Lactobacullus fermentus) obtenidas del cepario del Laboratorio de Biología Molecular de la FCS-UNT.

Las cepas BAL se sembraron en placas Petri con agar MRS (De Man, Rogosa y Sharpe) y azul de anilina y se incubaron por $48 \mathrm{~h}$ a $32^{\circ} \mathrm{C}$, para luego transferir $2-3$ colonias en tubos cónicos con $10 \mathrm{ml}$ de caldo MRS, incubando por $48 \mathrm{~h}$ a $35-40^{\circ} \mathrm{C}$ (Gámez et al., 2009). La concentración de cada BAL activada se homogenizó por espectrofotometría, donde la absorbancia o densidad óptica (DO) fue uno y la longitud de onda fue de $630 \mathrm{~nm}$ (Figura 1).

Para la preparación del inóculo se colocó $1 \mathrm{~L}$ de leche fresca en una olla a $85^{\circ} \mathrm{C}$ por 10 min y se dejó enfriar hasta $40^{\circ} \mathrm{C}$, para luego repartir en cuatro frascos de vidrio (250 $\mathrm{ml}$ ). Se agregó $2.5 \mathrm{ml}$ del caldo MRS con las BAL en cada frasco y se incubó a $40{ }^{\circ} \mathrm{C}$ por $18 \mathrm{~h}$.

\section{Preparación del yogurt}

Se tomó $50 \mathrm{ml}$ de la cepa activada como inóculo de cada frasco y se colocó en $1 \mathrm{~L}$ de leche pasteurizada. Se dejó incubar a $40{ }^{\circ} \mathrm{C}$ por $5 \mathrm{~h}$, y luego se colocó en refrigeración para su conservación y posterior uso. 


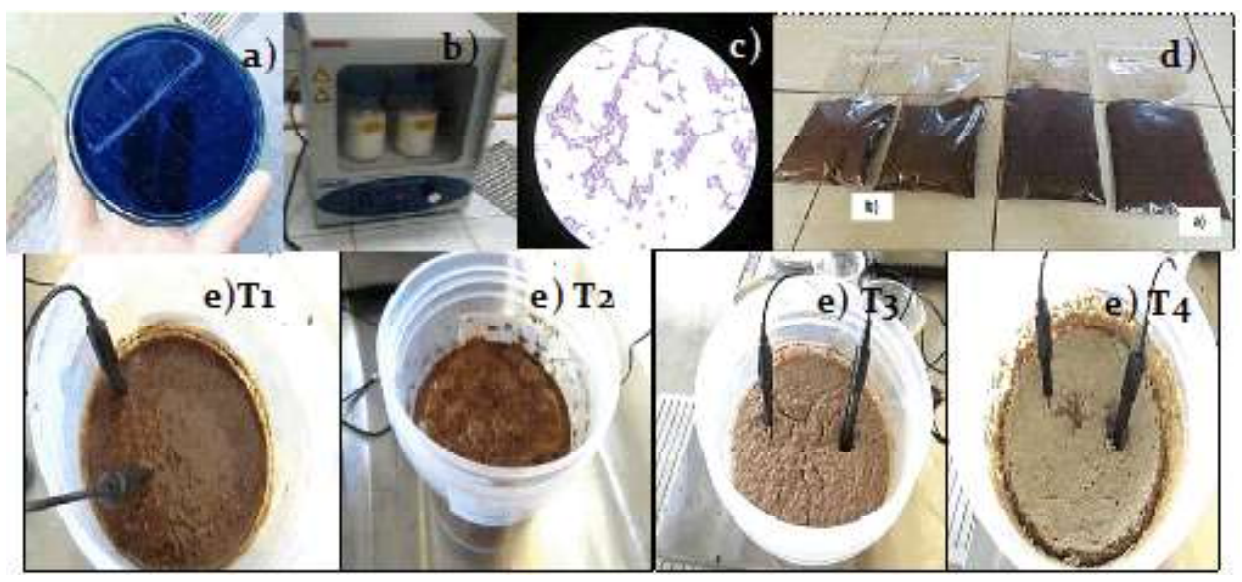

Figura 1. Preparación del ensilado biológico de cabeza de langostino y residuos de pescado, a) Selección de las BAL en MRS y azul de anilina, b) incubación c) Tinción de BAL, Ensilado Molido final: d) a) langostino, b) pescado. Muestreo final e) T1 = Cabeza de langostino con melaza y yogurt; e) T2 = Cabeza de langostino con polvillo y yogurt; e) $\mathrm{T} 3=$ Residuo de pescado con melaza y yogurt; y e) T4 = Residuo de pescado con polvillo y yogurt

Cuadro 1. Frecuencia de colecta de muestras del ensilado biológico para los análisis de laboratorio

\begin{tabular}{ccccc}
\hline \multirow{2}{*}{$\begin{array}{c}\text { Tiempo } \\
\text { (días) }\end{array}$} & \multicolumn{4}{c}{ Tipo de análisis } \\
\cline { 2 - 5 } & Fisicoquímico & Microbiológico & Valor nutricional & Organoléptico \\
\hline 3 & $\mathrm{x}$ & & $\mathrm{x}$ & $\mathrm{x}$ \\
4 & $\mathrm{x}$ & & & $\mathrm{x}$ \\
5 & $\mathrm{x}$ & & & $\mathrm{x}$ \\
7 & $\mathrm{x}$ & & $\mathrm{x}$ \\
15 & $\mathrm{x}$ & $\mathrm{x}$ & $\mathrm{x}$ & $\mathrm{x}$ \\
30 & $\mathrm{x}$ & $\mathrm{x}$ & $\mathrm{x}$ & $\mathrm{x}$ \\
\hline
\end{tabular}

\section{Preparación del ensilado biológico}

La cabeza de langostino y los restos del fileteado de pescado espejo se pasaron por un hervor hasta cambio de color (5-10 min) para disminuir la carga microbiana. Se trituró en una licuadora - molino y se mezcló según los tratamientos. Así, se tuvo $2 \mathrm{~kg}$ en cada balde por tratamiento. Se utilizó $70 \%$ del residuo cocinado (langostino o pescado), $25 \%$ del sustrato (melaza o polvillo de arroz) y $5 \%$ del yogurt. La mezcla total se colocó en depósitos plásticos transparentes de $4 \mathrm{~L}$ de capacidad que fueron tapados herméticamente, dejando un $25 \%$ de espacio libre entre el producto y la tapa (Figura 1).

La evaluación del ensilado se realizó en el laboratorio de biología molecular de la FCSUNT, según las frecuencias indicadas en el Cuadro 1. 


\section{Análisis Microbiológico}

Se mezcló $25 \mathrm{~g}$ de la muestra en $225 \mathrm{ml}$ de agua peptonada (medio diluyente), se filtró (papel $150 \mathrm{~mm}$ ) y se separó $1 \mathrm{ml}$ para hacer diluciones seriadas $\left(10^{-1}, 10^{-2}, 10^{-3} \mathrm{y}\right.$ $\left.10^{-4}\right)$. Se colocaron $100 \mu 1$ de cada dilución en placas Petri para cada recuento específico, por duplicado, y se sembraron siguiendo la técnica por extensión en placa e incubación invertida:

- Para el recuento de mesófilos aerobios se utilizó el medio Plate Count. incubado a $35^{\circ} \mathrm{C}$ por $48 \mathrm{~h}$ en placa invertida.

- El recuento de las BAL se hizo en medio de Man, Rogosa y Share (MRS), al cual se adicionó $300 \mu 1$ del colorante azul de anilina por cada $100 \mathrm{ml}$ de agar. Se incubó a $37^{\circ} \mathrm{C}$ por $48 \mathrm{~h}$. Adicionalmente, se realizó un frotis con algunas colonias para la confirmación de BAL.

- Recuento de salmonella, en el medio específico para salmonella (Agar Salmonella Shigella).

- El recuento de mohos y levaduras se hizo en el agar oxitetraciclina glucosa extracto de levadura (OGYE). Se incubó a $22{ }^{\circ} \mathrm{C}$ por 5-7 días en placa invertida.

En estos análisis se siguieron las indicaciones de asepsia requeridas (DIGESA, 2001; Serna y Stouvenel, 2005; Bou et al., 2011) en cámara de flujo laminar (Labotecgroup.com, modelo BBS-DDC).

\section{Análisis Organoléptico}

Se evaluaron las características organolépticas del ensilado biológico: color, olor y consistencia (Morón 2010; Spanopoulos et al., 2010; Chachapoya, 2013; Perea Román et al., 2017) en forma directa, en los tiempos indicados en el Cuadro 1.

\section{Análisis Fisicoquímico}

Se llevó a cabo en los tiempos indicados en el Cuadro 1. La toma de temperatura y $\mathrm{pH}$ fue directa. Además, se extrajo $10 \mathrm{~g}$ de muestra para la medición de la acidez titulable (en condiciones de asepsia), con el menor tiempo posible de exposición del ensilado, considerando que las BAL son facultativas y seguirán el proceso de fermentación (Toro y Concha, 2016).

- Temperatura: Se utilizó un termómetro convencional para leche.

- $\quad p H$ : Se utilizó el potenciómetro ADWA, modelo AD1020, colocando los electrodos directamente dentro de los recipientes de los ensilados, siguiendo las recomendaciones de Iglesias y Pérez (2016).

- Acidez titulable (\%): Se empleó el método de Martínez Prada (2003). El gasto de $\mathrm{NaOH}$ por el factor 0.09 fue asumido como ácido láctico de la muestra (Pérez e Iglesias, 2016).

\section{Análisis del Valor Nutricional}

Para determinar la composición del ensilado se realizó un secado previo siguiendo el método oficial de la AOAC $\left(70^{\circ} \mathrm{C}\right)$ por $48 \mathrm{~h}$, en particular para alimentos ricos en azúcares (Greenfield y Southgate, 2006). Las muestras fueron posteriormente molidas, tamizadas y envasadas en fundas herméticas para su evaluación en base seca.

La determinación de composición proximal del ensilado biológico se realizó en el laboratorio de evaluación nutricional de alimentos de la Universidad Agraria La Molina, siguiendo los protocolos del manual de análisis de alimentos del LENA-UNALM (2009): Método AOAC (2005) 984.13, Método AOAC (2005) 962.09, AOCS Official Procedure Am 5-04, AOCS Approved Procedure Ba 6a-05, AOAC (2005) 942.05.

\section{Análisis Estadístico}

Los datos obtenidos de temperatura y $\mathrm{pH}$ fueron sometidos a análisis de varianza y las diferencias significativas entre tratamientos fueron determinadas mediante la prueba de Duncan a un nivel de confianza de $95 \%$. En los análisis estadísticos de utilizó el programa estadístico INFOSTAT. 


\section{Resultados}

En los tratamientos T2 y T4, utilizando polvillo de arroz como sustrato, no se logró una adecuada fermentación, por lo que solo fueron evaluados por cinco días. El $\mathrm{pH}$ obtenido fue de 6.93 y 6.42 , respectivamente, $\mathrm{y}$ con olores desagradables.

\section{Análisis Fisicoquímico}

\section{Temperatura}

Los valores promedios de temperatura se incrementaron con respecto al tiempo de fermentación (Figura 2). En los tratamientos $\mathrm{T} 1$ y T3 se identificaron valores mínimos 28.95 y $29.35{ }^{\circ} \mathrm{C}$ a los 3 días y valores máximos 32.60 y $32.80^{\circ} \mathrm{C}$ a los 15 días de tiempo de fermentación, pero sin diferencias significativas entre ellos (Figura 2; Cuadro 2).
Los tratamientos $\mathrm{T} 2$ y T4, a los cuales se le agregó polvillo de arroz como sustrato, no prosperaron, ya que las BAL no generaron acidez ( $\mathrm{pH}$ de 6.93 y 6.42, respectivamente), toda vez que la actividad bacteriana requiere de sustratos húmedos (Lunkes, 2015; Pacheco y Sánchez, 2015) y pH menor a 4.5 (Hernández et al., 2015).

\section{Acidez titulable}

Se presentaron variaciones de acidez durante el proceso de almacenamiento del ensilado (Figura 3; Cuadro 2), encontrándose diferencias significativas entre los tratamientos $\mathrm{T} 2=0.39 \%$ y $\mathrm{T} 4=0.73 \%$ con 1 os tratamientos $\mathrm{T} 1=2.96 \%$ y $\mathrm{T} 3=3.08 \%$ $(\mathrm{p}<0.05)$. La producción de acidez se fue incrementando con el consiguiente descenso del $\mathrm{pH}$.

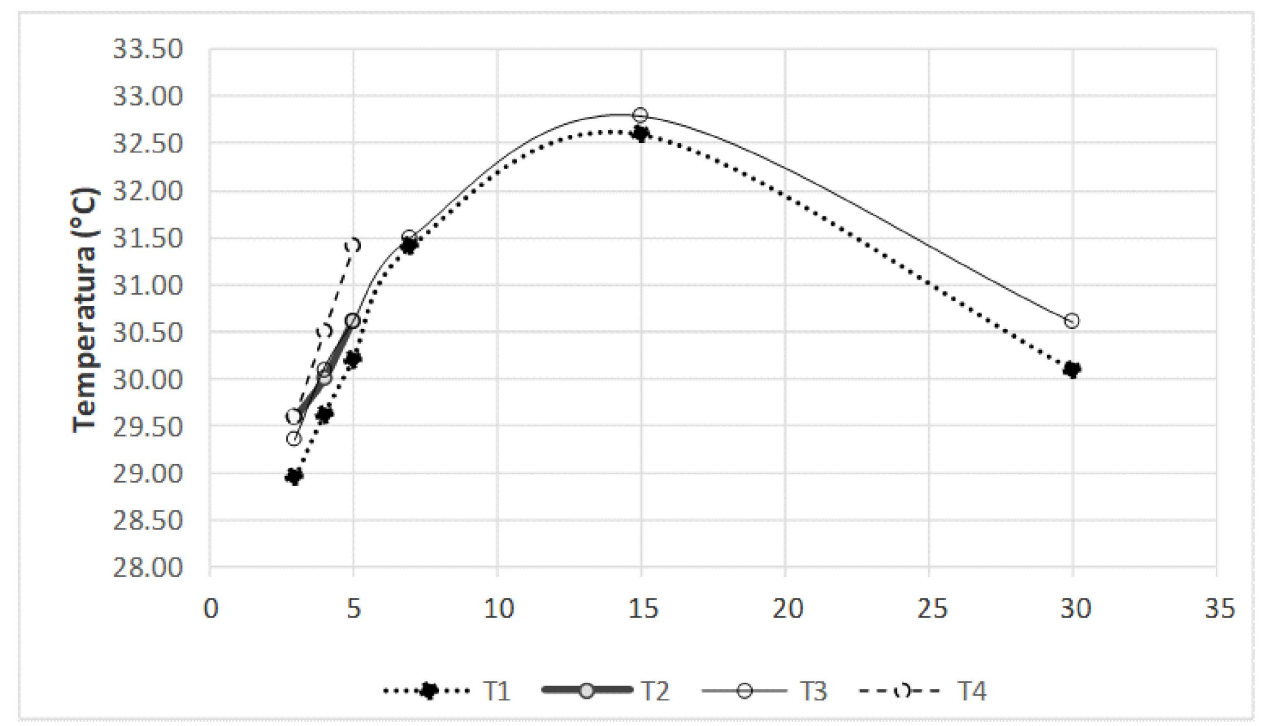

\section{Dias de evaluación}

Figura 2. Variación de temperatura del ensilado biológico de cabeza de langostino y residuos de pescado, según el tiempo de almacenamiento. $T 1=$ Cabeza de langostino con melaza y yogurt; $T 2=$ Cabeza de langostino con polvillo y yogurt; $T 3=$ Residuo de pescado con melaza y yogurt; y T4 = Residuo de pescado con polvillo $y$ yogurt 


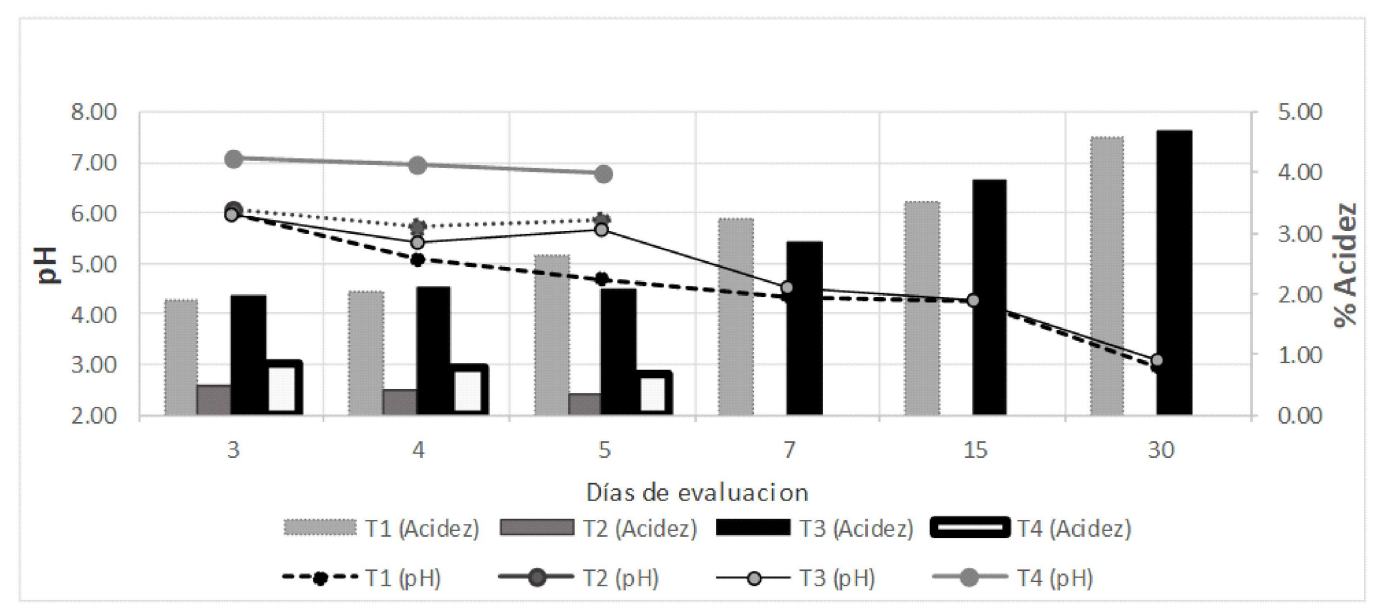

Figura 3. Comportamiento de $\mathrm{pH}$ y acidez del ensilado biológico de cabeza de langostino y residuos de pescado, de acuerdo con el tiempo de almacenamiento. $T 1=$ Cabeza de langostino con melaza y yogurt; T2 = Cabeza de langostino con polvillo $y$ yogurt; T3 = Residuo de pescado con melaza y yogurt; y $T 4=$ Residuo de pescado con polvillo y yogurt

Cuadro 2. Test de comparación de Duncan para el análisis físico del ensilado biológico de cabeza de langostino y residuos de pescado

\begin{tabular}{cccc}
\hline Tratamiento & $\begin{array}{c}\text { Temperatura } \\
\left({ }^{\circ} \mathrm{C}\right)\end{array}$ & $\mathrm{pH}$ & $\begin{array}{c}\text { Acidez } \\
(\%)\end{array}$ \\
\hline $\mathrm{T} 1$ & $29.77 \pm 2.48^{\mathrm{ab}}$ & $4.59 \pm 0.43 \mathrm{~cd}$ & $2.96 \pm 0.46^{\mathrm{ab}}$ \\
$\mathrm{T} 2$ & $15.15 \pm 262.56^{\mathrm{bc}}$ & $6.42 \pm 0.38^{\mathrm{b}}$ & $0.20 \pm 0.04^{\mathrm{cd}}$ \\
$\mathrm{T} 3$ & $30.02 \pm 2.61^{\mathrm{a}}$ & $4.68 \pm 0.78^{\mathrm{c}}$ & $3.08 \pm 0.85^{\mathrm{a}}$ \\
$\mathrm{T} 4$ & $15.31 \pm 268.22^{\mathrm{c}}$ & $6.93 \pm 0.01^{\mathrm{a}}$ & $0.36 \pm 0.15^{\mathrm{c}}$ \\
\hline
\end{tabular}

$a, b, c, d$ Superíndices diferentes dentro de columnas indican diferencia significativa $(p<0.05)$

$\mathrm{T} 1$ = Cabeza de langostino con melaza y yogurt; $\mathrm{T} 2$ = Cabeza de langostino con polvillo y yogurt; $\mathrm{T} 3=$ Residuo de pescado con melaza y yogurt; y T4 = Residuo de pescado con polvillo y yogurt

$p H$

Se encontraron diferencias significativas entre los tratamientos $\mathrm{T} 2$ y T4 $(\mathrm{pH} 6.42$ y 6.93) con T1 у T3 (4.59 y 4.68) (Figura 3; Cuadro 2).

\section{Análisis Microbiológico}

T1 y T3 mostraron un comportamiento similar durante el periodo de almacenamiento existiendo diferencias mínimas de recuento microbiano (Cuadro 3). Las BAL presentaron un alto crecimiento $\left(7.5 \times 10^{4} \mathrm{UFC} / \mathrm{ml}\right.$ en T1 y $8.0 \times 10^{5} \mathrm{UFC} / \mathrm{ml}$ en T3) a los 15 días, para ir disminuyendo al final del periodo de almacenamiento. El recuento de levaduras y hongos fue de crecimiento lento (T1 con $6.0 \times 10^{3}$ y T3 con $5.0 \times 10^{3} \mathrm{UFC} / \mathrm{ml}$ al final del almacenamiento. La bacteria patógena Salmonella sp no fue aislada. 
Cuadro 3. Parámetros microbiológicos del ensilado biológico de cabeza de langostino y residuos de pescado a los 15 y 30 días del almacenamiento

\begin{tabular}{lcccc}
\hline & \multicolumn{2}{c}{$\mathrm{T} 1$} & \multicolumn{2}{c}{$\mathrm{T} 3$} \\
\cline { 2 - 5 } & $15 \mathrm{~d}$ & $30 \mathrm{~d}$ & $15 \mathrm{~d}$ & $30 \mathrm{~d}$ \\
\hline $\begin{array}{l}\text { BAL } \\
\text { (UFC/ml) }\end{array}$ & $7.5 \times 10^{4}$ & $2.70 \times 10^{4}$ & $8.0 \times 10^{5}$ & $6.0 \times 10^{2}$ \\
$\begin{array}{l}\text { Mesófilos aerobios } \\
\text { (UFC/ml) }\end{array}$ & $5.5 \times 10^{4}$ & $1.0 \times 10^{4}$ & $4.0 \times 10^{5}$ & $3.0 \times 10^{3}$ \\
$\begin{array}{l}\text { Levadura y hongos } \\
\text { (UFC/ml) }\end{array}$ & $3.5 \times 10^{5}$ & $6.0 \times 10^{3}$ & $2.08 \times 10^{6}$ & $5.0 \times 10^{3}$ \\
Salmonella $\mathrm{sp}$ & Ausencia/25 g & Ausencia/25 g & Ausencia/25 g & Ausencia/25 g \\
\hline
\end{tabular}

${ }^{1}$ Bacterias ácido-lácticas

$\mathrm{T} 1$ = Cabeza de langostino con melaza y yogurt; T3 = Residuo de pescado con melaza y yogurt

Cuadro 4. Características organolépticas del ensilado biológico de cabeza de langostino y residuos de pescado durante el periodo de almacenamiento

\begin{tabular}{|c|c|c|c|c|c|c|c|c|}
\hline \multirow{2}{*}{$\begin{array}{l}\text { Paráme- } \\
\text { tro }\end{array}$} & \multirow{2}{*}{$\begin{array}{l}\text { Trata- } \\
\text { miento }\end{array}$} & \multirow{2}{*}{$\begin{array}{l}\text { Repeti- } \\
\text { ción }\end{array}$} & \multicolumn{6}{|c|}{ Tiempo (días) } \\
\hline & & & 3 & 4 & 5 & 7 & 15 & 30 \\
\hline \multirow[t]{4}{*}{ Color } & \multirow[t]{2}{*}{$\mathrm{T} 1$} & 1 & $\begin{array}{l}\text { Marrón } \\
\text { oscuro }\end{array}$ & $\begin{array}{l}\text { Marrón } \\
\text { oscuro }\end{array}$ & $\begin{array}{l}\text { Marrón } \\
\text { oscuro }\end{array}$ & $\begin{array}{l}\text { Marrón } \\
\text { oscuro }\end{array}$ & Marrón claro & $\begin{array}{l}\text { Marrón } \\
\text { claro }\end{array}$ \\
\hline & & 2 & $\begin{array}{l}\text { Marrón } \\
\text { oscuro }\end{array}$ & $\begin{array}{l}\text { Marrón } \\
\text { oscuro }\end{array}$ & $\begin{array}{l}\text { Marrón } \\
\text { oscuro }\end{array}$ & $\begin{array}{l}\text { Marrón } \\
\text { oscuro }\end{array}$ & Marrón claro & $\begin{array}{l}\text { Marrón } \\
\text { claro }\end{array}$ \\
\hline & \multirow[t]{2}{*}{$\mathrm{T} 3$} & 1 & $\begin{array}{l}\text { Marrón } \\
\text { oscuro }\end{array}$ & $\begin{array}{l}\text { Marrón } \\
\text { oscuro }\end{array}$ & $\begin{array}{l}\text { Marrón } \\
\text { oscuro }\end{array}$ & $\begin{array}{l}\text { Marrón } \\
\text { oscuro }\end{array}$ & Marrón claro & $\begin{array}{l}\text { Marrón } \\
\text { claro }\end{array}$ \\
\hline & & 2 & $\begin{array}{l}\text { Marrón } \\
\text { oscuro }\end{array}$ & $\begin{array}{l}\text { Marrón } \\
\text { oscuro }\end{array}$ & $\begin{array}{l}\text { Marrón } \\
\text { oscuro }\end{array}$ & $\begin{array}{l}\text { Marrón } \\
\text { oscuro }\end{array}$ & Marrón claro & $\begin{array}{l}\text { Marrón } \\
\text { claro }\end{array}$ \\
\hline \multirow[t]{4}{*}{ Olor } & \multirow[t]{2}{*}{$\mathrm{T} 1$} & 1 & $\begin{array}{l}\text { Dulce y } \\
\text { langostino } \\
\text { fresco }\end{array}$ & $\begin{array}{l}\text { Ácido } \\
\text { suave }\end{array}$ & Ácido suave & Ácido fuerte & Ácido fuerte & $\begin{array}{l}\text { Ligeramente } \\
\text { ácido y } \\
\text { dulce }\end{array}$ \\
\hline & & 2 & $\begin{array}{l}\text { Dulce y } \\
\text { langostino } \\
\text { fresco }\end{array}$ & $\begin{array}{l}\text { Ácido } \\
\text { suave }\end{array}$ & Ácido suave & Ácido fuerte & Ácido fuerte & $\begin{array}{l}\text { Ligeramente } \\
\text { ácido y } \\
\text { dulce }\end{array}$ \\
\hline & \multirow[t]{2}{*}{$\mathrm{T} 3$} & 1 & $\begin{array}{l}\text { Dulce y } \\
\text { pescado } \\
\text { fresco }\end{array}$ & $\begin{array}{l}\text { Ácido } \\
\text { fuerte }\end{array}$ & Ácido fuerte & Ácido fuerte & Ácido fuerte & $\begin{array}{l}\text { Ligeramente } \\
\text { ácido y } \\
\text { dulce }\end{array}$ \\
\hline & & 2 & $\begin{array}{l}\text { Dulce y } \\
\text { pescado } \\
\text { fresco }\end{array}$ & $\begin{array}{l}\text { Ácido } \\
\text { fuerte }\end{array}$ & Ácido fuerte & Ácido fuerte & Ácido fuerte & $\begin{array}{l}\text { Ligeramente } \\
\text { ácido y } \\
\text { dulce }\end{array}$ \\
\hline \multirow{4}{*}{$\begin{array}{l}\text { Consis- } \\
\text { tencia }\end{array}$} & \multirow[t]{2}{*}{$\mathrm{T} 1$} & 1 & Pastosa & Pastosa & Semilíquida & Semilíquida & Semilíquida & Semilíquida \\
\hline & & 2 & Pastosa & Pastosa & Semilíquida & Semilíquida & Semilíquida & Semilíquida \\
\hline & \multirow[t]{2}{*}{$\mathrm{T} 3$} & 1 & Pastosa & Pastosa & Semilíquida & Semilíquida & Semilíquida & Semilíquida \\
\hline & & 2 & Pastosa & Pastosa & Semilíquida & Semilíquida & Semilíquida & Semilíquida \\
\hline
\end{tabular}

$\mathrm{T} 1$ = Cabeza de langostino con melaza y yogurt; $\mathrm{T} 3$ = Residuo de pescado con melaza y yogurt 
Cuadro 5. Composición proximal de los ensilados biológicos de cabeza de langostino y residuos de pescado en base fresca a los 30 días de almacenamiento.

\begin{tabular}{lccccccc}
\hline Tratamiento & $\begin{array}{c}\text { Muestra } \\
(\mathrm{g})\end{array}$ & $\begin{array}{c}\text { Humedad } \\
(\%)\end{array}$ & $\begin{array}{c}\text { Proteína } \\
(\%)\end{array}$ & $\begin{array}{c}\text { Grasa } \\
(\%)\end{array}$ & $\begin{array}{c}\text { Fibra } \\
\text { cruda } \\
(\%)\end{array}$ & $\begin{array}{c}\text { Ceniza } \\
(\%)\end{array}$ & $\begin{array}{c}\text { ELN }^{1} \\
(\%)\end{array}$ \\
\hline T1 inicial & 540.00 & 60.04 & 23.37 & 1.35 & 4.93 & 13.39 & 56.96 \\
T1 final & 310.00 & 60.55 & 25.40 & 16.17 & 0.23 & 10.09 & 48.34 \\
T3 inicial & 550.00 & 70.62 & 33.08 & 20.69 & 9.12 & 12.01 & 25.09 \\
T3 final & 346.00 & 68.11 & 35.42 & 27.31 & 5.46 & 10.29 & 21.54 \\
\hline
\end{tabular}

${ }^{1}$ Extracto libre de nitrógeno

$\mathrm{T} 1$ = Cabeza de langostino con melaza y yogurt; T3 = Residuo de pescado con melaza y yogurt

\section{Análisis Organoléptico}

En el Cuadro 4, se aprecia las características organolépticas del EB. T1 y T3 presentaron un color marrón oscuro los primeros 7 días, llegando luego a una tonalidad de marrón claro. El olor entre los 3 y 4 días fue ácido suave en T1, mientras que en T3 fue ácido fuerte a partir del día 3, terminando el día 30 con un olor ligeramente ácido y dulce. La consistencia pastosa inicial pasó a consistencia semilíquida a partir del día 5 de almacenamiento.

\section{Valor Nutricional}

Los tratamientos T1 y T3 cumplieron con las características organolépticas y fisicoquímicas requeridas (Cuadro 5).

\section{Discusión}

La viabilidad de la fermentación del ensilado mediante la evaluación de las variables fisicoquímicas, microbiológicas y nutritivas es determinante para poder reconocerlo como un insumo apropiado para la alimentación animal.

La temperatura reportada en el estudio, entre 28 y $32{ }^{\circ} \mathrm{C}$, se encuentra dentro de los rangos recomendados para la viabilidad de fermentación del ensilado. Durante el almacenamiento o incubación presentó el mayor valor a los 15 días $\left(32.6-32.8^{\circ} \mathrm{C}\right)$, como es indicado en el proceso de fermentación de ensilados biológicos artesanales (Hoyo et al., 2006). La temperatura es estable al haber disminuido la fermentación, estando entre 27 y $28{ }^{\circ} \mathrm{C}$, como es reportado en el proceso de elaboración del ensilado a temperatura ambiental (Lezcano et al., 2015; Montaño et al., 2016). La velocidad de fermentación se determina cuando la temperatura se estabiliza, indicando que la incubación es viable, la cual se presentó desde los 7 a los 30 días de incubación, lo cual no afecta el proceso de fermentación ni la calidad de ensilado de origen pesquero utilizados para la alimentación de cerdos (Spanopoulos et al., 2010; Hernández et al., 2015; Lezcano et al., 2015; Rivero et al., 2016; Valenzuela, 2016).

La estabilidad del ensilado es monitoreada con la temperatura de fermentación, la cual se consigue a partir del día 7 de fermentación y se mantiene hasta al final del estudio (30 días). La temperatura está determinada por el metabolismo de las bacterias ácido-lácticas, mayormente bacterias mesófilas, que operan entre 25 y $40{ }^{\circ} \mathrm{C}$ en ensilados de residuos de pescado fresco y de desechos de frutas (Guzmán et al., 2012, Hernández et al., 2015; Iglesias y Pérez, 2016). 
El pH está relacionado inversamente con la acidez, e influenciado por el metabolismo de las BAL del ensilado y, por consiguiente, de la estabilidad de este, al evitar la proliferación de microrganismos que producen la pudrición del alimento. En los tratamientos $\mathrm{T} 1$ y T3 se obtuvieron $\mathrm{pH}$ menores a 4.5 , valores similares a ensilados reportados por Triana et al. (2014) de 4.30 en productos agroindustriales y por González y Marín (2005) de 4.5 en ensilado para sardinas. Así mismo, se reportan porcentajes mayores a $2.9 \%$ de acidez titulable en ensilados producidos con BAL (Serna y Stouvenel, 2005; Holguín et al., 2009; Barrera, 2011), mientras que la acidez encontrada en este trabajo fue de 2.96 y $3.08 \%$ para T1 y T3 . Llanes et al. (2007) y Martínez Prada (2003) mencionan que bajos niveles de $\mathrm{pH}$ permiten tener más confianza de que las características del ensilado no se vean alteradas por la presencia de microorganismos indeseables, dándole al ensilado características microbiologicas apropiadas para ser utilizado como alimento para cerdos.

Las BAL incorporadas en el ensilado, incluido Lactobacullus fermentus son consideradas las mejores fermentadoras y se utilizan en el ensilado como bactericidas naturales en la alimentacion de cerdos (Gámez et al., 2009; Flores et al., 2015), organismos naturales que se encuentran en el tracto digestivo en los vertebrados y son utilizados para fermentar el alimento y hacerlos mas eficientes para su uso en la alimentacion de cerdos (Hernández et al., 2015; Lezcano, et al., 2015).

La viabilidad de la fermentación del ensilado biológico para consumo animal depende de valores microbiológicos permisibles como los reportados por Toledo y Llanes (2006). Los resultados de T1 y T3 son aceptables al cumplir con estos parámetros. Roussos y Perraud-Gaime (1996) y Bou et al. (2011) indican que los microrganismos no deseados deben estar por debajo de límite permisible $\left(10 \times 10^{7} \mathrm{UFC} / \mathrm{g}\right)$. De igual forma, el recuento de levaduras y hongos con valores $6.0 \times 10^{3}$ y $5.0 \times 10^{3}$ se encuentran dentro del límite permisible de $10 \times 10^{4} \mathrm{UFC} / \mathrm{g}$, según la norma técnica de Colombia en alimento balanceado (Ottati y Bello 1992; SánchezTrujillo et al., 2016). Por otro lado, la ausencia de microorganismos patógenos como Salmonella sp pone a manifiesto que han podido ser inhibidos con la acidez del ensilado generada por las BAL (Gámez et al., 2009; Bou et al., 2011; Rivas y Leonardo, 2013).

Las características organolépticas de $\mathrm{T} 2$ y T4, utilizando polvillo como sustrato, evidenciaron olores desagradables, consistencia muy pastosa y color rosado pálido, convirtiéndolos en ensilados inaceptables. Según Sánchez et al. (2015), el sustrato utilizado para el ensilado debe contener más del 50\% de humedad (el polvillo de arroz tiene 10\%); así mismo, López et al. (2014) indican que la melaza como sustrato ( $60 \%$ de humedad) proporciona un ensilado con mejores características organolépticas, color amarronado grisáceo claro, consistencia líquida y olor ácido suave, que coinciden con los estudios de Mendoza y Carrasco (2007) y ParisuañaCallata et al. (2018). Además a mayor tiempo de almacenamiento el ensilado se hace más liviano en consistencia y desarrolla un agradable olor a malta (Lezcano et al., 2015; Arévalo, 2016; Montaño et al., 2016).

El ensilado aumenta los valores de proteína cruda, tal y como se observa en el presente estudio (T1: $23.37 \%$ y T3: $33.08 \%$ al inicio y $\mathrm{T} 1: 25.40 \%$ y $\mathrm{T} 3: 35.42 \%$ al final del periodo de almacenamiento), como ha sido reportado por Valencia Castillo (2011). Es así que el ensilado contiene mas del $20 \%$ de proteína, el cual es el nivel minimo indicado para ser considerado como insumo proteico (Wattiaux et al., 1998). No obstante, estos nieveles dependen de la especie de pescado, época de captura, tipo y proporción de los residuos de pescado (Ngoan et al., 2000; Balsinde et al., 2003; Gonzales y Marín, 2005; Toledo y Llanes, 2006; Mendoza y Carrasco, 2007). 


\section{Conclusiones}

- El fermentador BAL Lactobacillus fermentus es apropiado para la preparación de ensilado biológico.

- El seguimiento de la temperatura, $\mathrm{pH}$, porcentaje de acidez titulable, así como de las características microbiológicas y nutritivas permiten determinar la viabilidad del ensilado biológico.

- Las características organolépticas del ensilado utilizando la melaza como sustrato fueron adecuadas, mientras que el empleo de polvillo de arroz como sustrato no permitió obtener un ensilado adecuado.

- El porcentaje de proteína cruda del ensilado de cabeza de langostino como el de residuos de pescado es adecuado para ser considerado como alimento de origen animal para cerdos.

\section{Agradecimientos}

Los autores agradecen a la Universidad Nacional de Tumbes por el apoyo incondicional a la investigación.

\section{Literatura Citada}

1. Ambrosio MJ. 2004. Procesamiento pesquero, disposición de residuos, e impacto ambiental. En: Congreso Argentino de Saneamiento y Medio Ambiente. Buenos Aires, Argentina.

2. Arévalo A. 2016. Fermentación láctica de la cáscara de camarón con Lactobacillus delbrueckii para obtención de quitina. Tesis de Ingeniero Químico. Quito, Ecuador: Escuela Politécnica Nacional. 159 p.

3. Balfagón A, Jiménez-Moreno E. 2014. Nuevos avances en alimentación y nutrición porcina: bases científicas y alimentación práctica en la península ibérica. En: XXX Curso de especialización FEDNA. Madrid.
4. Balsinde M, Fraga I, Galindo J. 2003. Inclusión de ensilado de pescado como alternativa en la elaboración de alimento extruido para el camarón de cultivo (Litopenaeus schmitti). En: II Congreso Iberoamericano Virtual de Acuicultura. La Habana: CIVA.

5. Báñez A, González C, Castellanos D, Araque H, Tepper R. 2017. Comportamiento de cerdos en etapa de iniciación alimentados con fuentes proteicas de origen sanguíneo. Rev Unellez Cienc Tecnol 23: 14-18.

6. Barrera R. 2011. Producción de ácido láctico mediante el uso de Lactobacillus rhamnosus, a partir de melaza. Tesis de Ingeniería de Alimentos. Ecuador: Univ. Técnica de Ambato. $118 \mathrm{p}$.

7. Bou G, Fernández-Olmos A, García C, Sáez-Nieto JA, Valdezate S. 2011. Métodos de identificación bacteriana en el laboratorio de microbiología. Enferm Infec Microbiol Clín 29: 601-608. doi: 10.1016/j.eimc.2011.03.012

8. Caicedo W, Rodríguez R, Lezcano P, Ly J, Vargas JC, Uvidia H, Samaniego E, et al. 2018. Rectal digestibility of nutrients in growing pigs, fed with taro silage (Colocasia esculenta (L) Schott). Technical note. Cuban J Agr Sci 51: 337-341.

9. Castro M, Martínez M. 2015. La alimentación porcina con productos no tradicionales: cincuenta años de investigaciones en el Instituto de Ciencia Animal. Cuban J Agr Sci 49: 189-196.

10. Chachapoya D. 2013. Producción de alimentos balanceados en una planta procesadora en el cantón Cevallos. Tesis de Ingeniero Industrial. Quito, Ecuador: Escuela Politécnica Nacional. 135 p.

11. DIGESA. 2001. Manual de análisis microbiológico de alimentos. Manual, Ministerio de la salud, Lima. [Internet]. Disponible en: http://bvs.minsa.gob.pe/local/ DIGESA/61_MAN.ANA.-MICROB.-pdf

12. Flores L, Elías A, Proaño F, Granizo $G$ Medina Y, López S, Herrera $F$, et al. 2015. Effects of a commercial antibiotic and a microbial preparation on 
the productive performance and pigs health during fattening. Cuban J Agr Sci 49: 377- 388 .

13. Gámez HJ, Aguirre D, Ramírez C. 2009. Caracterización de bacterias probióticas aisladas del intestino grueso de cerdos como alternativa al uso de antibióticos. Revista MVZ Cordoba 14: 1723-1735. doi: 10.21897/rmvz.356

14. González D, Marín M. 2005. Obtención de ensilados biológicos a partir de los desechos del procesamiento de sardinas. Rev Cient Fac Cien V 15: 560-567.

15. Greenfield H, Southgate DAT. 2006. Datos de composición de alimentos: obtención, gestión y utilización. Roma: Organización de las Naciones Unidas para la Agricultura y la Alimentación. 312 p.

16. Guzmán O, Lemus C, Martínez $S$, Bonilla J, Plasencia A, Ly J. 2012. Características químicas del ensilado de residuos de mango (Mangifera indica $\mathrm{L}$.) destinado a la alimentación animal. Cuban J Agr Sci 46: 369-374.

17. Hernández YG Sosa D, Boucourt R, Scull I. 2015. Caracterización química de un alimento ensilado para cerdos. Nota técnica. Cuban J Agr Sci 49: 91-92.

18. Holguín MS, Caicedo LA, Veloza LC. 2009. Estabilidad de almacenamiento de ensilados biológicos a partir de residuos de pescado inoculados con bacterias ácido-lácticas. Rev Fac Med Vet Zootec 56: 95-104.

19. Hoyo GD, Pellicer K, Copes J. 2006. Producción de ensilado de pescado en baja escala para uso de emprendimientos artesanales. Analecta Vet 26: 5-8.

20. Iglesias JE, Pérez JT. 2016. Evaluación de los desechos frescos de pescado y ensilados como única fuente de proteína animal en la alimentación de híbrido de Clarias (Clarias gariepinus x $C$. macrocephalus). Aquatic 25: 22-27.

21. Lezcano P, Vázquez, A, Bolaños A, Piloto JL, Martínez M, Rodríguez $Y$. 2015. Ensilado de alimentos alternativos, de origen cubano, una alternativa técni- ca, económica y ambiental para la producción de carne de cerdo. Cuban J Agr Sci 49: 65-69.

22. Llanes J, Toledo J, Fernández I, Lazo J. 2007. Estudio del ensilado biológico de pescado como inóculo de bacterias lácticas en la conservación de desechos pesqueros. REDVET 7(9). [Internet]. Disponible en: http:// www.veterinaria.org/revistas/redvet/ n090907/090728.pdf

23. López F, Gomez G, Ortiz M, Perea C. 2014. Evaluación del ensilaje de vísceras de tilapia roja (Oreochromis spp) en alimentación de pollos de engorde. Biotecnol Sector Agropec Agroind 12: 106-114

24. Lunkes J. 2015. Purificação e caracterização bioquímica de xilanase-I produzida por Penicillium crustosum e sua aplicação. Tesis de Maestría, Paraná, Brasil: Universidade Estadual do Oeste do Paraná. 48 p.

25. Martínez R. 2003. Producción de un ensilado biológico a partir de vísceras de pescado de la especie Prochilodus mariae (coporo), Pseudoplatystoma fasciatum (bagre rayado) y Phractocephalus hemiliopterus (cajaro). Tesis de Ingeniero Ambiental. Colombia: Univ. Nacional de Colombia. $83 \mathrm{p}$.

26. Mendoza M, Carrasco J. 2007. Efecto del inóculo de yogurt sobre el nivel de bases volátiles nitrogenadas totales en el ensilado biológico de cabezas de langostino. Tumbes, Perú: Univ. Nacional de Tumbes. $32 \mathrm{p}$.

27. Montaño CM, Quiñonez LQ, Orejuela KWI, Zamora FAS. 2016. Alternativa de alimentación para cerdos en ceba condiciones locales de producción. Investigación Saberes 5(2): 78-83.

28. Morón Machado T. 2010. Silagem biológica de pescado. [Internet]. Disponible en: ftp://ftp.sp.gov.br/ftppesca/ CDTF23mar.pdf 
29. Ngoan LD, An LV, Ogle B, Lindberg JE. 2000. Ensiling techniques for shrimp by-products and their nutritive value for pigs. Asian-Australas J Anim Sci 13: 1278-1284. doi: 10.5713/ajas.2000.1278

30. Ottati G, Bello R. 1992. Ensilado microbiano de pescado en la alimenta ción porcina. I. Valor nutritivo del producto en dietas para cerdos. En: Consulta de Expertos sobre Tecnología de Productos Pesqueros en América Latina. Roma: FAO. p 69-79.

31. Pacheco Y, Sánchez M. 2015. Efecto de dietas con ensilado biológico de residuos de partes blandas de Argopecten purpuratus como sustituto de la harina de pescado, en la digestibilidad aparente de la proteína en alevines de Colossoma macropomum «gamitana». Tesis de Biólogo Acuicultor. Chimbote, Perú: Univ. Nacional del Santa. $45 \mathrm{p}$.

32. Parisuaña-Callata J, ChuracutipaMamani M, Salas A, Barriga-Sánchez M, Araníbar M. 2018. Ensilado de residuos de trucha en la alimentación de ovinos de engorde. Rev Inv Vet Perú 29: 151-160. doi: 10.15381/rivep.v29i1.14160

33. Perea C, Hoyos JL, Garcés YJ, Arboledal M, Stella L, Peñaranda G, Ader J. 2017. Evaluación de procesos para obtener ensilaje de residuos piscícolas para alimentación animal. Cienc Desarrollo 8: 39-50.

34. Ponce LE, Gernat AG. 2002. The effect of using different levels of tilapia by-product meal in broiler diets. Poult Sci 81: 1045-1049. doi: 10.1093/ps/81.7.1045

35. Rivero R, Puente H, Salgado J. 2016. Conservación de residuos pesqueros con lactosuero ácido y miel B de caña de azúcar. Rev Comp Prod Porcina 23: 28-37.

36. Roussos S, Perraud-Gaime I. 1996. Fisiología y bioquímica de microorganismos utilizados en procesos de fer- mentación en medio sólido. En: México: Congreso Nacional de Biotecnología y Bioingeniería.

37. Samuels WA, Fontenot JP, Allen VG, Abazinge MD. 1991. Seafood processing wastes ensiled with straw: utilization and intake by sheep. J Anim Sci 69: 49834992. doi: 10.2527/1991.69124983x

38. Sánchez H, Benites E, Ubillus E, Ochoa $\boldsymbol{G}$ 2015. Efecto de tres niveles de ensilado biológico de cabeza de Penaeus, en alimentación de cerdos (Sus escrofa) en las etapas fisiológicas de gestación y lactación. Manglar 10: 27-38.

39. Sánchez H, Ochoa G. 2016. Producción y valoración de alimentos para animales monogástricos, con ensilado biológico de restos del procesamiento de langostino (Litopenaeus vannamei) fermentados con lactobacilos. Scientia Agropec 7: 181-189.

40. Sánchez-Trujillo SM, Hurtado-Pinzón AJ, Toro-Silva J, Hoyos-Concha JL. 2016. Evaluación a nivel piloto del proceso de ensilaje biológico de residuos de Oncorhynchus mykiss. Agronomía Colombiana 34: 1303-1307.

41. Serna-Cock L, Stouvenel ARD. 2005. Producción biotecnológica de ácido láctico: estado del arte. Cienc Tecnol Aliment 5: 54-65. doi: 10.1080/11358120509487672

42. Spanopoulos-Hernandez M, PoncePalafox JT, Barba-Quintero G, Ruelas-Inzunza JR, TiznadoContreras MR, Hernández-González C, Shirai K. 2010. Producción de ensilados biológicos a partir de desechos de pescado, del ahumado de atún aleta amarilla (Thunnus albacares) y del fileteado de tilapia (Oreochromis sp), para la alimentación de especies acuícolas. Rev Mex Ing Quím 9: 167-178. 
43. Toledo J, Llanes J. 2006. Estudio comparativo de los residuos de pescado ensilados por vías bioquímicas y biológicas. Aquatic 25: 28-33.

44. Toledo J, Llanes J. 2016. Estudio comparativo de los residuos de pescado ensilados por vías bioquímica y biológica. Aquatic 25: 28-33.

45. Toro RO, Concha JLH. 2016. Residuos piscícolas a ensilaje biológico: evaluación fisicoquímica. Publ Invest 10: 1320. doi: $10.22490 / 25394088.1584$

46. Triana E, Leal F, Campo Y, Lizcano H. 2014. Evaluación de ensilaje a partir de dos subproductos agroindustriales (cáscara de naranja y plátano de rechazo) para alimentación de ganado bovino. Alimentos Hoy 22: 33-45.
47. Valencia Castillo A. 2011. Actividad de la hormona IGH-1 y metabolismo energético-proteico asociado a la inclusión de ensilado biológico de pescado en la dieta de terneros. Tesis de Maestría. Veracruz, México: Univ. Veracruzana. $71 \mathrm{p}$.

48. Valenzuela C. 2016. Ensilado de pescado seco: una alternativa tentadora para alimentación animal. Salmon Expert 41(6): 55-58.

49. Wattiaux MA, Homan J, del Carmen Moreno M, de Rodríguez AM. 1998. Nutrición y alimentación. Capítulo 2: Composición y análisis de alimentos. Instituto Babcock para Investigación y Desarrollo Internacional para la Industria Lechera. 